\title{
Dynamic Behavior of Silicon-Based Electrodes at Open Circuit Conditions
}

\author{
V. V. Emets, T. L. Kulova, and A. M. Skundin*
}

Frumkin Institute of Physical Chemistry and Electrochemistry, 31 Leninskii ave., 119071 Moscow, Russia

*E-mail: askundin@mail.ru

doi: $10.20964 / 2017.04 .25$

Received: 11 January 2017 / Accepted: 22 February 2017 / Published: 12 March 2017

The behavior of thin-film multi-layered silicon-based electrode during storage at open circuit conditions was studied for the first time by electrochemical impedance spectroscopy (EIS). The active part of electrode consisted of alternating layers of slightly oxidized silicon and Si-Al-O composite. It is found that self-discharge occurs during o.c.p. storage, and self-discharge current varies in chaotic manner. This phenomenon was explained by a dynamical character of SEI formation and destruction. The equivalent circuit comprising small inductance, ohmic resistance, and three parallel combinations of resistances and CPEs was proposed. The certain components of the equivalent circuit also undergo non-monotonous changes during the storage. This fact confirms dynamic character of SEI formation which manifests itself not only at the cycling but at open circuit conditions as well.

Keywords: electrochemical impedance spectroscopy; silicon composites; processes at electrode aging.

\section{$\underline{\text { FULL TEXT }}$}

(C) 2017 The Authors. Published by ESG (www.electrochemsci.org). This article is an open access article distributed under the terms and conditions of the Creative Commons Attribution license (http://creativecommons.org/licenses/by/4.0/). 